\title{
REPORTE
}

\section{PRIMER REPORTE DE NEFROPAT ÍA JUVENIL (DISPLASIA RENAL) EN UNA GOLDEN RETRIEVER}

\author{
Luis Tabacchi N. ${ }^{1}$, Alfonso Chavera C. ${ }^{1}$, Rosa Perales C. ${ }^{1,2}$, Nieves Sandoval Ch. ${ }^{1}$, \\ Gilberto Santillán A. ${ }^{1}$, César Palacios E. ${ }^{3}$ y Sandra Malca O. ${ }^{3}$
}

\section{Abstract}

\begin{abstract}
Juvenile nepropathy was diagnosed in a female Golden Retriever of three months of age, with clinical signs compatible with chronic renal failure. The diagnosis was based on the presence of persistent poorly differentiated renal tissue (immature glomeruli and tubules, and persistent mesenchyme) on histopathological examination.
\end{abstract}

Key words: nepropathy, Golden Retriever, renal tissue, pathology

Una hembra Golden Retriever de 3 meses de edad fue llevada en abril del 2002 a un consultorio particular para su evaluación debido a un repentino ataque convulsivo. El animal fue tratado durante dos semanas con suero y antibióticos. Los signos clínicos más notorios fueron vómitos, diarrea sanguinolenta, anorexia, disnea, y polidipsia. En el examen físico, la perra mostraba crecimiento retardado, estaba deprimida, deshidratada, con membranas mucosas pálidas y con temperatura rectal de $36.4{ }^{\circ} \mathrm{C}$. Se tomaron muestras para hemograma y bioquímica sanguínea. Los resultados indicaron una severa azotemia, hiperfosfatemia, hipocalcemia y anemia no regenerativa. La condición del animal siguió empeorando y falleció a los tres días de iniciado un nuevo tratamiento.
En la necropsia se observó caquexia, músculos pálidos y escasa grasa subcutánea. En la cavidad pélvica, ambos riñones se encontraban pequeños (4 x $3 \mathrm{~cm})$, pálidos, de forma irregular, con depresiones superficiales a manera de estrías, consistencia firme al corte y adherencia de la cápsula. Al examinar la sección sagital de los riñones (Fig. 1), se observó la presencia de múltiples quistes de $1 \mathrm{~mm}$ de diámetro a nivel cortical y bandas de tejido conectivo blanquecino que se extendían radialmente de la corteza a la médula. A nivel medular, el tejido conectivo se distribuía difusamente.

Las lesiones extrarenales consistían en una hiperplasia paratiroidea, severo edema pulmonar con focos múltiples de calcifica- 
ción, osteodistrofia fibrosa en mandíbula y cráneo, moderada glositis ulcerativa, severa gastroenteritis hemorrágica ulcerativa e hipertrofia cardiaca concéntrica.

Se encontraron alteraciones patológicas en glomérulos, túbulos e intersticio. Los glomérulos presentaban atrofia e hipercelularidad con dilatación del espacio urinario y a veces con material rosáceo homogéneo. La atrofia se caracterizaba por un lumen capilar poco evidente, hipertrofia del epitelio visceral e hipercromasia, localizado principalmente a nivel subcapsular y a veces en la profundidad de la corteza renal (Fig. 2). Además, se observaron otros glomérulos grandes con marcada hipercelularidad; algunas veces con patrón lobular, acompañados de moderado a severo incremento de la matriz mesangial, en tanto que en otras zonas se observó necrosis y esclerosis glomerular acompañada de colapso y fibrosis capsular periglomerular, adheridas al glomérulo.
Las lesiones encontradas en los túbulos de la porción cortical consistían en dilatación tubular focal a difusa de moderada severidad rodeada por células de epitelio plano. En otras zonas, el epitelio estaba tumefacto y vacuolado. En la porción medular se encontró túbulos atrofiados mayormente visibles en áreas de marcada fibrosis, y túbulos colectores dilatados, tortuosos con proliferación adenomatoide de epitelio (Fig. 3). Algunos túbulos, tanto en corteza como de médula, mostraban acumulación intraluminal de material rosáceo hialino (material proteináceo). En algunas zonas de la porción cortical se podría apreciar la deposición intra tubular de material compatible con cristales de oxalatos.

Las lesiones en intersticio consistían en moderada fibrosis segmental a difusa. Las estrías de tejido fibroso se extendían de la corteza a la médula dentro de la cual se encontraban entremezclados glomérulos pequeños y grandes con túbulos atróficos y dilata-

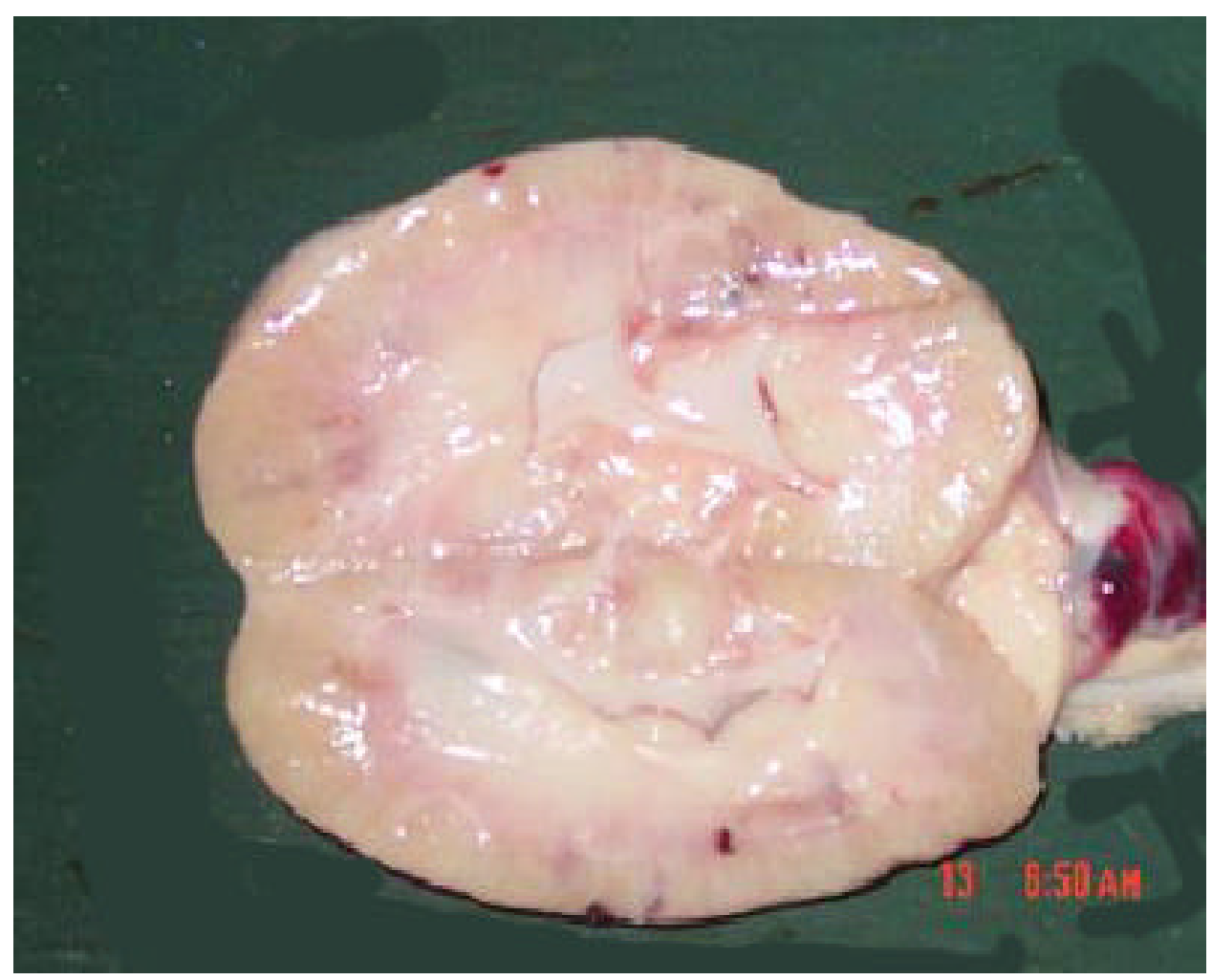

Figura 1. Quiste de $1 \mathrm{~mm}$ de diámetro 


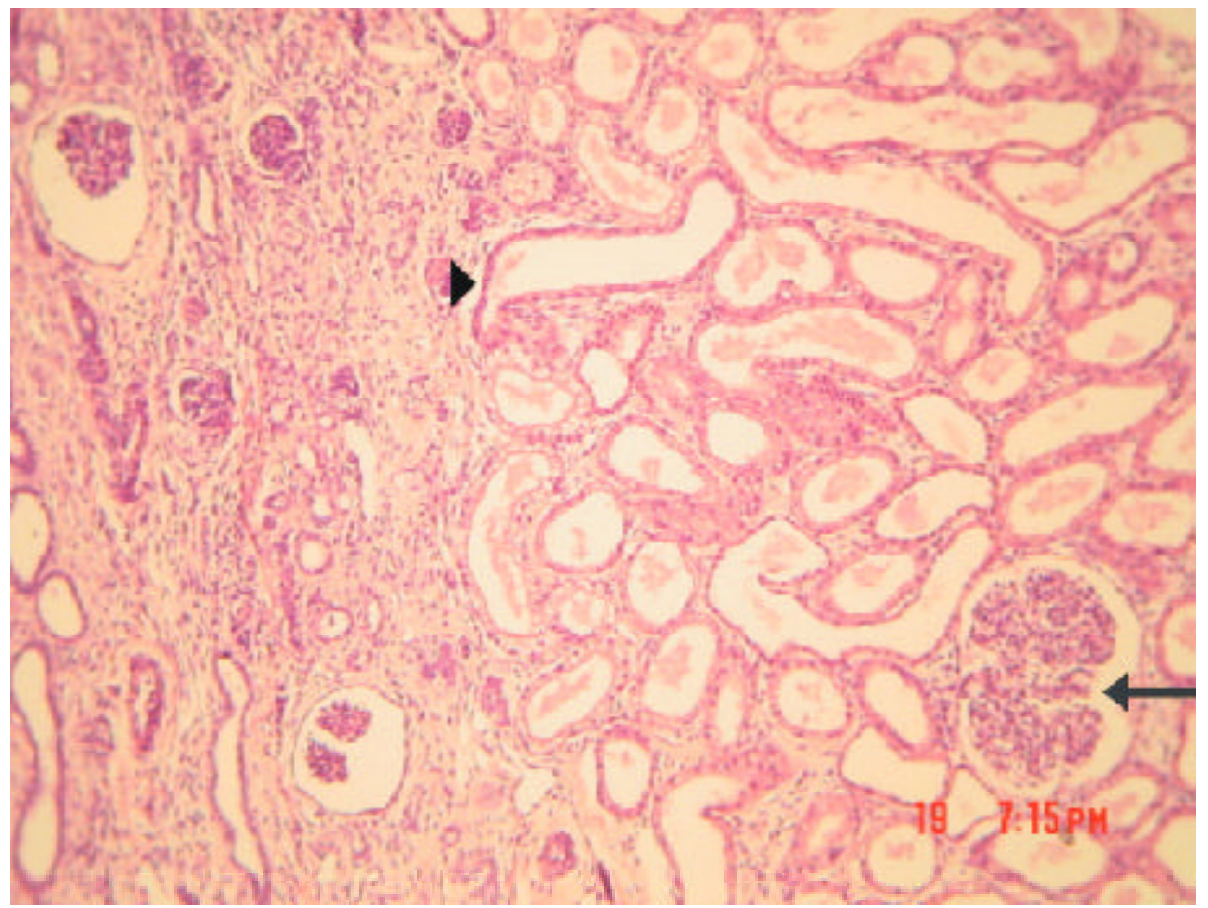

Figura 2. Microfotografía de la corteza renal. Nótese la hipercelularidad de algunos glomérulos (flecha larga) y otros de apariencia inmadura (cabeza de flecha). HE, 10x

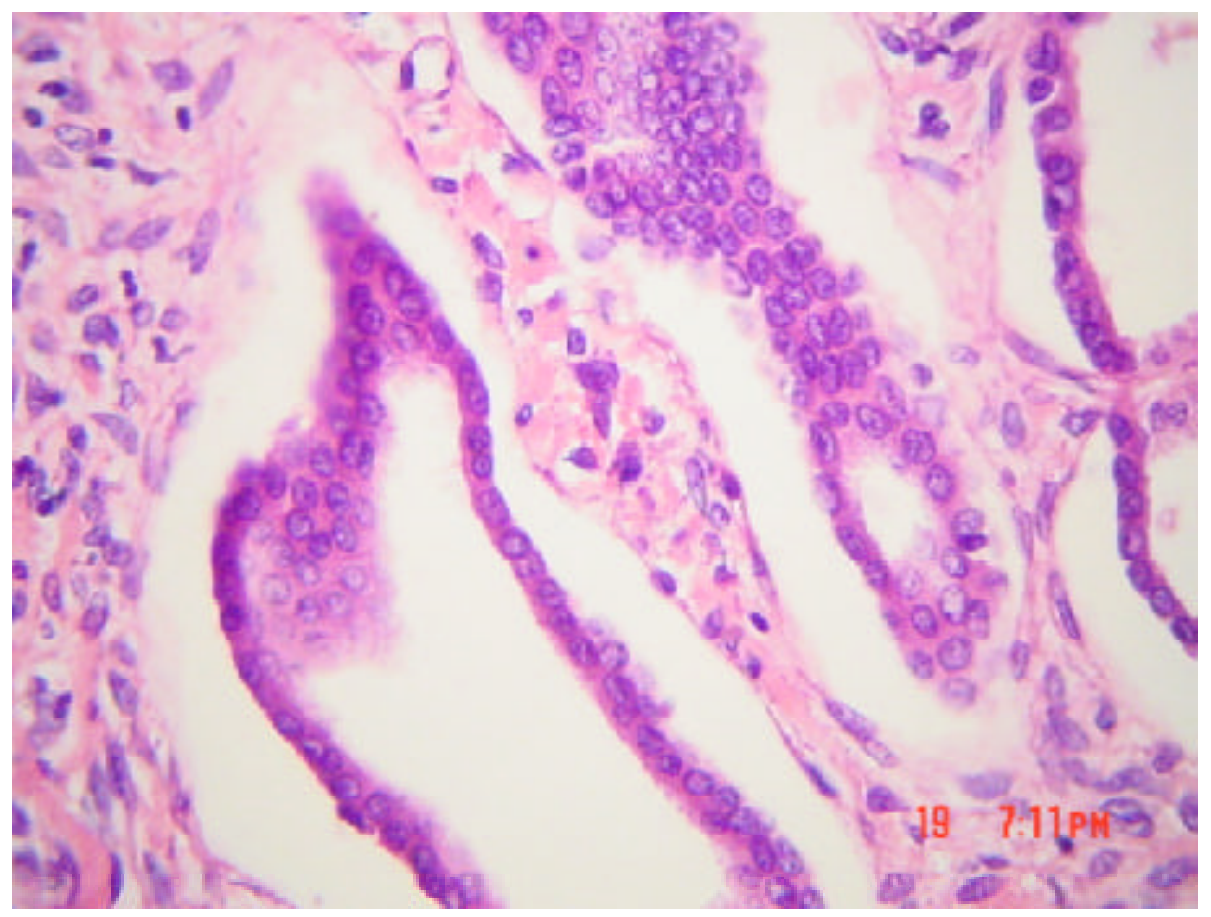

Figura 3. Microfotografía de la médula renal. Nótese la proliferación adematoide del túbulo colector. HE, 25x 
dos. La fibrosis medular fue más densa y difusa. El infiltrado celular linfoplasmático se localizó en la corteza, distribuyéndose radialmente en el intersticio o de manera focal, cerca de la unión córtico medular. Áreas focales de mineralización intersticial fueron observadas tanto en corteza como en médula. Las arteriolas mostraban proliferación de la capa media y un lumen moderadamente estrecho.

La terminología usada para describir enfermedades renales juveniles es aún controvertida en el campo de la Medicina Veterinaria (Potter et al., 2000). El término nefropatía juvenil es usado por algunos autores para describir enfermedades renales en perros inmaduros y adultos jóvenes no asociadas con enfermedad renal primaria (Confer, 1992; Martínez, 1998; Maxie, 1990) y nefropatía familiar cuando las bases familiares han sido determinadas. La nefropatía juvenil incluye una variedad de enfermedades morfológicas como la agenesia, hipoplasia, displasia, glomerulopatía, nefropatía túbulo intersticial y disfunción en el transporte tubular, siendo descrita en 21 razas caninas (Potter et al., 2000). Así mismo, en Samoyedos se ha descrito una patología hereditaria ligada al sexo, parecida al Síndrome de Alport, descrito en humanos (Martínez, 1998; Maxie, 1990).

La perra del presente reporte tenía tres meses de edad. La insuficiencia renal puede manifestarse en cachorros y perros adultos, pero en la mayoría de los casos se presenta entre los 3 a 18 meses de edad (Maxie, 1990), con promedios de 12 a 13 meses en Golden Retrievers (De Morais y Di Bartola, 1996; Kerlin y Van Winkle, 1995).

Los hallazgos clínicos en el animal de este reporte eran los esperados para un perro con falla renal crónica (FRC) e incluían vómitos, anorexia, polidipsia, pérdida de peso y diarrea sanguinolenta (Chew y Di Bartola, 1983; Robinson y Hustable, 1985). La poliurea no fue informada por el dueño, quizá debido a una falta de atención en las costumbres del animal. Las convulsiones son frecuentes en la falla renal aguda, y su intensidad está relacionada con la velocidad evolutiva del fracaso renal. Éste sería el primer reporte de este signo clínico en esta raza a una temprana edad debido a FRC. El crecimiento enano y la osteodistrofia fibrosa son observados a menudo en perros con FRC y fue observado en este caso. Similar hallazgo ha sido reportado en Golden Retrievers con enfermedad renal juvenil (De Morais y Di Bartola, 1996 ; Kerlin y Van Winkle, 1995).

El murmullo sistólico ha sido reportado en Golden Retrievers jóvenes con falla renal y las causas se atribuyen a una enfermedad hipertensiva del corazón, estenosis subaórtica, displasia de válvula mitral y severa anemia no regenerativa (De Morais y Di Bartola, 1996; Kerlin y Van Winkle, 1995). En el presente caso, no se auscultó el corazón en el examen clínico pero en la necropsia se encontró hipertrofia cardiaca concéntrica del ventrículo izquierdo, significativo de una enfermedad hipertensiva del corazón, a lo que se añade la anemia no regenerativa encontrada, lo cual hace pensar que el murmullo sistólico pudo estar presente.

Los hallazgos de laboratorio fueron los esperados en una FRC: azotemia, hiperfosfatemia, hipocalcemia, anemia normocítica normocrómica (Chew y Di Bartola, 1983; Robinson y Hustable, 1985). Otras anormalidades incluyeron hipercoles-teronemia y baja gravedad específica de la orina (Chew y Di Bartola, 1983; Robinson y Hustable, 1985). La azotemia se explica por la incapacidad del riñón para excretar los desechos nitrogenados del catabolismo proteico (Cheville, 1981). Los niveles elevados de fósforo se deben a una filtración glomerular reducida (Cheville,1994). La acumulación de fósforo en el plasma deprime el calcio plasmático induciendo hiperplasia paratiroidea y secreción de PTH (Cheville, 1981, 1994). Pese a que la hipocalcemia es frecuente en otras razas con enfermedad renal familiar, en reportes con 
Golden Retrievers es más común encontrar hipercalcemia ((De Morais y Di Bartola, 1996; Kerlin y Van Winkle, 1995). La anemia encontrada se debe al daño renal que lleva una hipoproducción de eritropoyetina ocasionando una eritropoyesis disminuida (Cheville, $1981 ; 1994)$.

Las lesiones macroscópicas en riñón son similares a las reportadas en Golden Retrievers con displasia renal (De Morais y Di Bartola, 1996; Kerlin y Van Winkle, 1995). Las lesiones extrarenales encontradas son compatibles con uremia y han sido reportadas en esta raza (De Morais y Di Bartola, 1996; Kerlin y Van Winkle, 1995), así como en otras razas (Chew y Di Bartola, 1983; Robinson y Hustable, 1985). Lesiones renales microscópicas similares a las del Golden Retriever se han observado en Lhasa Apso, Shih Tzu (O’Brien et al., 1982), Norwegian Elkhound (Finco et al., 1977) y Samoyedo (Martínez, 1998; Maxie, 1990) e incluían infiltrado linfoplasmático, severa fibrosis intersticial a nivel medular y mineralización en las membranas basales.

Glomérulos de patrón lobular con leve a moderado incremento de la matriz mesangial se han descrito en Doberman Pincher (Chew y Di Bartola, 1983) y Cocker Spaniel (Robinson y Hustable, 1985). La fibrosis periglomerular, atrofia glomerular quística, esclerosis glomerular y glomérulos de apariencia fetal se han descrito en varias razas (Finco et al., 1977; Chew y Di Bartola, 1983; De Morais y Di Bartola, 1996; Kerlin y Van Winkle, 1995; Martínez, 1998; Maxie, 1990; O’Brien et al., 1982; Di Bartola y Chew, 1983; Potter et al., 2000).

Las lesiones puramente glomerulares como las del Rottweiler no se han encontrado en este reporte (Cook y Fean, 1993). La proliferación epitelial adenomatoide de los túbulos colectores (epitelio tubular atípico) se ha observado claramente en este caso, pero no así en otros reportes con Golden Retrievers (De Morais y Di Bartola, 1996; Kerlin y Van
Winkle, 1995). Esta alteración también se ha encontrado en otras razas (Finco et al., 1977; Chew y Di Bartola, 1983; O’ Brien et al., 1982; Martínez, 1998; Maxie,1990).

El término displasia renal se refiere al desarrollo desorganizado del parénquima renal causado por diferenciación anormal y está caracterizado por figuras histológicas inapropiadas para la edad del animal, que llevan a una degeneración renal progresiva y a una temprana FRC (Martínez, 1998; Maxie, 1990; Potter et al., 2000; Robinson y Hustable, 1985). La observación del glomérulo con apariencia fetal (diferenciación asincrónica del nefrón) y proliferación adenomatoide del túbulo colector en este reporte es compatible con el diagnóstico de displasia renal (De Morais y Di Bartola, 1996; Kerlin y Van Winkle, 1995). Otros autores mencionan que se requiere la presentación de tres alteraciones adicionales para ser llamada displasia renal: mesénquima persistente, ductos metanéfricos persistentes y metaplasia disontogénica (Picut y Lewis, 1987); sin embargo, la persistencia de tejido pobremente diferenciado (glomérulos fetales) y estructuras anómalas (epitelio tubular atípico) implican una inducción del blastema metanéfrico que fallaron en recibir una diferenciación completa (Potter et al., 2000).

La importancia clínica de este reporte es que debe sospecharse de displasia renal en perros Golden Retrievers jóvenes e inmaduros con hallazgos clínicos y resultados de laboratorio indicativos de enfermedad renal. El pronóstico en estos casos es reservado. Éste es el primer reporte de esta enfermedad en el Perú.

\section{Literatura Citada}

1. Confer, A. 1992. The urinary system: progressive juvenile nepropathy. En: Special Veterinary Pathology. Thompson, S. (ed). $2^{a}$ ed. p 238-240. Ed. Mosby. USA. 
2. Cook, S.; D. Fean. 1993. Renal failure attributable to atrophic glomerupathy in four related Rottweilers. J. Am. Vet. Med. Assoc. 202: 107-109.

3. Cheville, N. 1981. Patología celular. p 125-128. Ed. Acribia. España.

4. Cheville, N. 1994. Introducción a la anatomía patológica general veterinaria. $\mathrm{p}$ 41-44. Ed. Acribia. España.

5. Chew, D.; S. Di Bartola. 1983. Juvenal renal disease in Doberman Pinchers dogs. J. Am. Vet. Med. Assoc. 182: 481-485.

6. Di Bartola, S.; D. Chew. 1983. Juvenile renal disease in related Standard Poodles. J. Am. Vet. Med. Assoc. 183: 693-696.

7. De Morais, H.S.; S.P. Di Bartola. 1996. Juvenal renal disease in Golden Retrievers (1984-1994). J. Am. Vet. Med. Assoc. 209: 792-797.

8. Finco, D.; J. Duncan; W. Crowel. 1977. Familial renal disease in Norwegian Elknound dogs: morphologic examinations. Am. J. Vet. Res. 38: 942-947.

9. Kerlin, R.; T. Van Winkle. 1995. Renal dysplasia in Golden Retrievers. Vet. Pathol. 32: 327-329.
10. Martínez, J. 1998. Aparato urinario: Enfermedad renal familiar. En: Patología Sistémica Veterinaria. Trigo, F.J. (ed). $3^{\text {a }}$ ed. p 98-135. Ed. McGraw-Hill. México.

11. Maxie, M. 1990. Sistema urinario: Enfermedad renal familiar. En: Patología de los animales domésticos. Jubb, K.V.; P.C. Kennedy; N. Palmer (eds). $3^{a}$ ed. p 406408. Ed. Hemisferio Sur. Uruguay.

12. O'Brien, T.; C. Osborne; D. Barns. 1982. Clinicopathologic manifestation of progressive renal disease in Lhapsa Apso and Shih Tzu dogs. J. Am. Vet. Med. Assoc. 180: 658-664.

13. Potter, D.; C. Clerck; M. Day. 2000. Juvenile nephopathy in a Boxer, a Rottweiler, a Collie, and a Irish Wolfhound. Aust. Vet. J. 78: 162-165.

14. Picut, C.; R. Lewis. 1987. Microscopic features of canine renal dysplasia. Vet. Pathol. 24: 156-163.

15. Robinson, W.; C. Hustable. 1985. Familial nephropathy in Cocker Spaniel. Aust. Vet. J. 62: 109-112. 